Supporting Information

\title{
Debromination of PBDEs in Arkansas Water Bodies Analyzed by Positive Matrix Factorization
}

\author{
Yonghong Zou†, Azivy Che Aziz-Schwanbeck§, Hua Weił, \\ Erik R. Christensen†*, Karl J. Rockne§, An Lił
}

+ Department of Civil and Environmental Engineering, University of Wisconsin-Milwaukee, Milwaukee, Wisconsin.

$¥$ §chool of Public Health, University of Illinois-Chicago, Chicago, Illinois.

$\S$ Department of Civil and Materials Engineering, University of Illinois-Chicago, Chicago, Illinois.

*Correspondence author email: erc@uwm.edu 
16S rRNA Gene Tag Sequencing and Data Analysis. The DNA isolation and quantification was performed as described previously. ${ }^{1}$ Briefly, Sediment samples kept at -40 ${ }^{\circ} \mathrm{C}$ were homogenized and $0.25 \mathrm{~g}$ was used for extraction using the Mobio PowerSoil ${ }^{\circledR}$ DNA isolation kit following the manufacturer's instructions (Mo Bio Laboratories, Carlsbad, CA). Power bead extraction tubes were used to disperse soil particles, dissolved humic acids, and to protect the nucleic acids from degradation. Further steps included addition of lysis solution, centrifugation, further addition of lysis solution, loading supernatant into spin filter, discarding the filtrate, and centrifugation of filter with DNA co-eluting solution of sterile solution buffer. DNA concentrations were determined using the nanodrop 2000 spectrophotometer (Thermo Scientific, Waltham, MA) and quality was checked using the optical density ratio $O D_{260} / O D_{280}$. Only extractions with $\mathrm{OD}_{260} / \mathrm{OD}_{280}$ between 1.7 and 1.9 were selected to ensure high quality DNA extracts. DNA extracts were stored at $-20^{\circ} \mathrm{C}$ until further analysis.

Bacterial tag-encoded FLX 454 amplicon pyrosequencing (bTEFAP) and data processing were conducted at Research and Testing Laboratory (Lubbock, TX, USA) as described previously. ${ }^{2,3}$ For this study, PCR amplification was performed using the primers Gray28F and Gray519R to span the ribosomal variable regions V1-V3 in relation to the $E$. coli $16 \mathrm{~S}$ gene. ${ }^{4}$ Each amplification was performed using a 35 cycle single PCR step with Qiagen HotStar Master Mix with addition of $0.5 \mu \mathrm{L}$ of Hot Star HiFidelity Polymerase (Qiagne Inc., Valencia, CA).

Estimates of Microbial Diversity. Taxonomic classification of the bacterial sequences in samples was carried out individually using the RDP classifier. Bacterial 16S rRNA gene sequences were aligned phylogenetically using the naïve Bayesian rRNA classifier with a bootstrap cutoff of $80 \%$ to assign the sequences to different taxonomic levels (http://rdp.cme.msu.edu/classifier/classifier.jsp). The normalized sequence set of each sample was also individually aligned using the bacteria-alignment model of the RDP. By applying the Complete-Linkage Clustering (or farthest neighbor), sequences in each sample were assigned to phylotype clusters at 3\% cutoff level (complete method available at the RDP Pyrosequencing Pipeline $\left.{ }^{5,6}\right)$. The sequences data were deposited, and are publicly available in the MG-RAST web-server $^{7}$ with the following accession numbers: 4487895.3, 4487896.3, 4487897.3, 4487898.3, 4487899.3, 4487900.3, 4487901.3, 4487902.3, 4487906.3, and 4487907.3.

PMF Analysis and Determination of Number of Factors. PMF analyses were carried out on both a MATLAB program previously developed in our group ${ }^{8}$ (referred to as B-PMF hereafter) and the EPA PMF 5.0 program ${ }^{9}$. Different number of factors have been tested in the PMF analyses, the model outputs and diagnostic parameters were examined to determine the number of factors. Specifically, the coefficient of determination (COD), the $Q$ values, and the model returned data errors are presented in Tables S4 to S7 for AED+ACL and AMW from these 
two model programs. The model estimated data error is indicated by comparing the true $Q$ value to the expected $Q$ value ( $Q$ (true)/ $Q$ (exp)) in EPA-PMF. Theoretically, a good model estimation may have a $Q$ value close to the total number of degrees of freedom, d.f. $=m^{*} n$ $p^{*}(n+m)$, where $m$ and $n$ are the number of compounds and samples, respectively, and $p$ is the number of factors. The data matrix $\mathbf{X}(m \times n)$ is written as a product of the loading $\mathbf{G}(m \times p)$ and contribution $\boldsymbol{F}(p \times n)$ matrices,

$$
\mathbf{X}=\mathbf{G} \mathbf{F}
$$

The $Q$ function to be minimized can be written as,

$$
\mathrm{Q}(\boldsymbol{E})=\sum_{i=\mathbf{1}}^{\boldsymbol{m}} \sum_{j=\mathbf{1}}^{n}\left(\frac{X_{i j}-\sum_{h=1}^{p} G_{i h} F_{h j}}{\boldsymbol{\sigma}_{i j}}\right)^{\mathbf{2}}
$$

which is the estimation of the summation of squared differences between measured and calculated values of the data matrix, comparing to the known or given data uncertainty $\left(\sigma_{i j}\right)$. Following the error structure adopted in Bzdusek, ${ }^{8}$ the data uncertainty was calculated by,

$$
\sigma_{i j}=\mathrm{C}_{1}+\mathrm{C}_{2}\left|X_{i j}\right|
$$

where $C_{1}$ is equal to the detection limit, and the given relative data error $C_{2}$ typically is between 0.05 and 0.3 . We used here $C_{2}=0.25$.

Robustness and convergence are other important factors that determine the number of factors. Both of the two programs monitor the convergence of the model simulation. The input max number of iterations in B-PMF will be reached and $Q$ calculated if the model fails to converge. Similarly, EPA-PMF, will mark the non-converging runs, along with the $Q$ values. In addition, the EPA-PMF uses bootstrap to test the robustness of the model simulation. A stable model output would be indicated by successful mapping of the factors in 100 bootstrap runs. BPMF does not conduct bootstrap simulation, however, the uncertainty or sensitivity to variations in input data was monitored by using a collection of data matrices generated by Monte Carlo. ${ }^{10}$ Specifically, for each B-PMF and EPA-PMF analysis, 10 data matrices were generated from the initial matrix. We ran here the model simulation on the 10 data matrices, and compared the results of these 10 runs to check the robustness of the model simulation. The model results were mapped through visual examination. And the results and variations presented are based on the 10 runs.

The number of factors was determined to be two for AED+ACL. The $Q$ value exhibits a dramatic decrease when the number of factors increases from one to two for AED+ACL dataset (B-PMF, Table S5). The point where the slope of the curve changes from steep to smooth is generally a good suggestion for number of factors. Because after this point, the goodness of 
model fit doesn't increase much as the number of factors increases. Another confirmation of is that the $Q$ (true)/ $Q$ (exp) value is close to one when the number of factors was set to be two. It suggests the given data error is appropriate.

Following the same idea, the number of factors for AMW dataset was determined to be four or five using both B-PMF and EPA-PMF (Tables S6 and S7). As shown in the following table, the EPA-PMF fails to map one of the factors (factor 2 ) in the bootstrap simulation. This indicates unstable model output when four factors are set for the AMW data. Instead, the robustness of model simulation dramatically increased when the number of factors was set to five. It is noteworthy that because both loading and contribution matrices contain several zeros in the cases considered here, rotational ambiguity is not a concern. ${ }^{11}$

\begin{tabular}{|c|c|c|c|c|c|c|}
\hline \multicolumn{7}{|c|}{ BS Mapping (No. of Factors $=4$ ): } \\
\hline & Factor 1 & Factor 2 & Factor 3 & Factor 4 & Unmapped & \\
\hline Boot Factor 1 & 100 & 0 & 0 & 0 & 0 & \\
\hline Boot Factor 2 & 21 & 30 & 13 & 32 & 4 & \\
\hline Boot Factor 3 & 0 & 0 & 100 & 0 & 0 & \\
\hline Boot Factor 4 & 0 & 0 & 0 & 100 & 0 & \\
\hline \multicolumn{7}{|c|}{ BS Mapping (No. of Factors = 5): } \\
\hline & Factor 1 & Factor 2 & Factor 3 & Factor 4 & Factor 5 & Unmapped \\
\hline Boot Factor 1 & 100 & 0 & 0 & 0 & 0 & 0 \\
\hline Boot Factor 2 & 0 & 100 & 0 & 0 & 0 & 0 \\
\hline Boot Factor 3 & 0 & 0 & 100 & 0 & 0 & 0 \\
\hline Boot Factor 4 & 1 & 0 & 6 & 91 & 0 & 2 \\
\hline Boot Factor 5 & 0 & 3 & 1 & 1 & 95 & 0 \\
\hline
\end{tabular}

\section{References}

(1) Zhao, X.; Rockne, K.J.; Drummond, .J.L.; Hurley, R.K.; Shade, C.W.; Hudson, R.J.M. Characterization of methyl mercury in dental wastewater and correlation with sulfate reducing bacterial DNA. Environ. Sci. Technol. 2008, 42, 2780-2786.

(2) Dowd, S.E.; Sun, Y.; Secor, P.R.; Rhoads, D.D.; Wolcott, B.M.; James, G.A.; Wolcott, R.D. Survey of bacterial diversity in chronic wounds using pyrosequencing, DGGE, and full ribosome shotgun sequencing. BMC Microbiol. 2008, 8, 43.

(3) Kostka, J.E.; Prakash, O.; Overholt, W.A.; Green, S.J.; Freyer, G.; Canion, A.; Delgardio, J.; Norton, N.; Hazen, T.C.; Huettel, M. Hydrocarbon-degrading bacteria and the bacterial community response in Gulf of Mexico beach sands impacted by the Deepwater Horizon oil spill. Appl. Environ. Microbiol. 2011, 77 (22), 7962-7974. 
(4) Ishak, H.D.; Plowes, R.; Sen, R.; Kellner, K.; Meyer, E.; Estrada, D.A.; Dowd, S.E.; Mueller, U.G. Bacterial diversity in Solenopsis invecta and Solenopsis geminata ant colonies characterized by 16S amplicon 454 pyrosequencing. Microb. Ecol. 2011, 61 (4), 821-831.

(5) Wang, Q.; Garrity, G.M.: Tiedje, J.M.; Cole, J.R. Naive Bayesian classifier for rapid assignment of rRNA sequences into the new bacterial taxonomy. Appl. Environ. Microbiol. 2007, 73, 5261-5267.

(6) Cole, J.R.; Wang, Q.; Cardenas, E.; Fish, J.; Chai, B.; Farris, R.J.; Kulam-Syed-Mohideen, A.S.; McGarrell, D.M.; Marsh, T.; Garrity, G.M.; Tiedje, J.M. The Ribosomal Database Project: improved alignments and new tools for rRNA analysis. Nucleic Acids Res. 2009, 37, D141-D145.

(7) Meyer, F.; Paarmann, D.; D’Souza, M.; Olson, R.; Glass, E.M.; Kubal, M.; Paczian, T.; Rodriguez, A.; Stevens, R.; Wilke, A.; Wilkening, J.; Edwards, R.A., The Metagenomics RAST server-a public resource for the automatic phylogenetic and functional analysis of metagenomes. BMC Bioinformatics 2008, 9, 386.

(8) Bzdusek P.A. PCB or PAH sources and degradation in aquatic sediments determined by positive matrix factorization. Ph.D. dissertation, University of Wisconsin-Milwaukee, Milwaukee, Wisconsin, 2005.

(9) US EPA Positive Matrix Factorization version 5.0, Human Exposure and Atmospheric Sciences. Washington, D.C., 2014, http://www.epa.gov/heasd/research/pmf/pmf_guidelines.html

(10) Bzdusek, P.A.; Christensen, E.R.; Lee,C.M.; Pakdeesusuk, U.; Freedman, D.L. PCB congeners and dechlorination in sediments of Lake Hartwell, South Carolina determined from cores collected in 1987 and 1998. Environ. Sci. Technol. 2006b, 40 (1), 109-119.

(11) Henry, R.C.; Christensen, E.R. Selecting an appropriate multivariate source apportionment model result. Environ. Sci. Technol. 2010, 43, 5739-5746.

The following pages contain a summary of physical/chemical parameters for sediment cores from AMW and AED+ACL (Table S1), and the PBDE data for CMB and PMF analyses (Tables S2 and S3). The diagnostics coefficients returned by EPA-PMF and B-PMF for AED+ACL and AMW are given in Tables S4S7. Site and total PBDE information is shown in Figs. S1-S2, technical mixture data in Fig. S3, and factor analytical results in Figs. S4-S8. 
Table S1. Summary of physical/chemical parameters sediments in this study. Sample data in bold denotes samples for which DNA extracts were obtained and sequenced (see Table 1).

\begin{tabular}{|c|c|c|c|c|c|c|c|}
\hline Site & $\begin{array}{l}\text { Avg Depth } \\
(\mathrm{cm})\end{array}$ & $\begin{array}{c}\text { TOC } \\
(\mathrm{mg} / \mathrm{g})\end{array}$ & $\begin{array}{c}\mathrm{OM} \\
(\mathrm{mg} / \mathrm{g})\end{array}$ & OC/OM & $\%$ solids & $\begin{array}{c}\text { Porosity } \\
\text { (\%) }\end{array}$ & $\begin{array}{l}\text { ORP } \\
(\mathrm{mV})\end{array}$ \\
\hline AED & 0.5 & 51.8 & 80.9 & 0.64 & 6.16 & 95.0 & -81 \\
\hline AED & 1.5 & 48.7 & 75.0 & 0.65 & 8.07 & 93.3 & \\
\hline AED & 2.5 & 46.8 & 70.4 & 0.66 & 9.24 & 92.3 & -100 \\
\hline AED & 3.5 & 46.3 & 88.0 & 0.53 & 8.84 & 92.1 & -80 \\
\hline AED & 4.5 & 45.8 & 75.3 & 0.61 & 14.4 & 93.8 & -75 \\
\hline AED & 5.5 & 42.6 & 72.7 & 0.59 & 14.1 & 93.8 & \\
\hline AED & 6.5 & 48.7 & 73.3 & 0.66 & 14.6 & 93.7 & -89 \\
\hline AED & 7.5 & 49.1 & 76.6 & 0.64 & 16.2 & 92.7 & -93 \\
\hline AED & 8.5 & 46.6 & 80.2 & 0.58 & 15.8 & 92.8 & -98 \\
\hline AED & 9.5 & 45.5 & 71.8 & 0.63 & 22.4 & 89.9 & \\
\hline AED & 10.5 & 44.2 & 67.8 & 0.65 & 22.6 & 90.6 & \\
\hline AED & 11.5 & 42.6 & 64.9 & 0.66 & 31.1 & 85.7 & -96 \\
\hline AED & 12.5 & 17.6 & 30.5 & 0.58 & 95.5 & 74.6 & -106 \\
\hline AED & 13.5 & 14.9 & 28.3 & 0.52 & 94.9 & 73.5 & -101 \\
\hline AED & 14.5 & 17.0 & 26.2 & 0.65 & 98.8 & 72.1 & -105 \\
\hline AED & 16 & 11.3 & 18.9 & 0.60 & 91.6 & 72.2 & -105 \\
\hline AED & 18 & 13.8 & 24.7 & 0.56 & 88.2 & 73.0 & -109 \\
\hline AED & 20 & 11.9 & 22.5 & 0.53 & 95.4 & 67.1 & -108 \\
\hline AED & 22 & 9.30 & 15.8 & 0.59 & 96.1 & 67.8 & -107 \\
\hline AED & 24 & 8.38 & 14.5 & 0.58 & 95.8 & 67.6 & -109 \\
\hline $\mathrm{ACL}$ & 0.5 & 54 & 95 & 0.57 & 16 & 93.1 & -100 \\
\hline $\mathrm{ACL}$ & 1.5 & 53 & 92 & 0.58 & 17 & 92.4 & -130 \\
\hline $\mathrm{ACL}$ & 2.5 & 50 & 97 & 0.52 & 21 & 90.4 & -112 \\
\hline $\mathrm{ACL}$ & 3.5 & 48 & 81 & 0.59 & 23 & 89.6 & -70 \\
\hline $\mathrm{ACL}$ & 4.5 & 46 & 78 & 0.59 & 25 & 89.0 & \\
\hline $\mathrm{ACL}$ & 5.5 & 46 & 78 & 0.58 & 26 & 87.9 & -47 \\
\hline $\mathrm{ACL}$ & 6.5 & 42 & 66 & 0.63 & 30 & 86.4 & -8.3 \\
\hline $\mathrm{ACL}$ & 7.5 & 41 & 68 & 0.61 & 30 & 85.9 & -8.8 \\
\hline $\mathrm{ACL}$ & 8.5 & 40 & 65 & 0.61 & 32 & 85.4 & -1.3 \\
\hline $\mathrm{ACL}$ & 9.5 & 42 & 75 & 0.56 & 31 & 85.6 & \\
\hline $\mathrm{ACL}$ & 10.5 & 41 & 70 & 0.58 & 34 & 84.4 & 1.2 \\
\hline $\mathrm{ACL}$ & 11.5 & 29 & 56 & 0.52 & 34 & 83.7 & \\
\hline $\mathrm{ACL}$ & 12.5 & 31 & 58 & 0.53 & 34 & 83.4 & 13 \\
\hline $\mathrm{ACL}$ & 13.5 & 36 & 66 & 0.54 & 32 & 85.0 & \\
\hline $\mathrm{ACL}$ & 14.5 & 36 & 65 & 0.55 & 32 & 84.8 & 19 \\
\hline $\mathrm{ACL}$ & 16 & 37 & 68 & 0.55 & 32 & 84.9 & 24 \\
\hline
\end{tabular}


Table S1, continued.

\begin{tabular}{|c|c|c|c|c|c|c|c|}
\hline Site & $\begin{array}{l}\text { Avg Depth } \\
\text { (cm) }\end{array}$ & $\begin{array}{c}\text { TOC } \\
(\mathrm{mg} / \mathrm{g})\end{array}$ & $\begin{array}{c}\mathrm{OM} \\
(\mathrm{mg} / \mathrm{g})\end{array}$ & $\mathrm{OC} / \mathrm{OM}$ & $\%$ solids & $\begin{array}{c}\text { Porosity } \\
\text { (\%) }\end{array}$ & $\begin{array}{l}\text { ORP } \\
(\mathrm{mV})\end{array}$ \\
\hline $\mathrm{ACL}$ & 18 & 40 & 74 & 0.54 & 33 & 84.2 & 18 \\
\hline $\mathrm{ACL}$ & 20 & 42 & 73 & 0.57 & 34 & 84.0 & \\
\hline $\mathrm{ACL}$ & 22 & 67 & 131 & 0.51 & 37 & 81.2 & 29 \\
\hline $\mathrm{ACL}$ & 24 & 51 & 84 & 0.61 & 50 & 72.0 & 29 \\
\hline $\mathrm{ACL}$ & 27.5 & 22 & 32 & 0.66 & 67 & 76.8 & 24 \\
\hline $\mathrm{ACL}$ & 32.5 & 22 & 42 & 0.53 & 58 & 79.2 & 18 \\
\hline $\mathrm{ACL}$ & 37.5 & 22 & 26 & 0.84 & 66 & 78.0 & 28 \\
\hline AMW & 1 & 312 & 474 & 0.66 & 1.49 & 99.2 & -23 \\
\hline AMW & 3 & 304 & 460 & 0.66 & 1.96 & 99.0 & -22 \\
\hline AMW & 5 & 295 & 451 & 0.66 & 2.29 & 98.8 & -21 \\
\hline AMW & 7 & 282 & 445 & 0.63 & 2.56 & 98.7 & -22 \\
\hline AMW & 9 & 284 & 439 & 0.65 & 2.86 & 98.5 & \\
\hline AMW & 11 & 287 & 440 & 0.65 & 2.99 & 98.5 & -25 \\
\hline AMW & 13 & 251 & 437 & 0.57 & 3.14 & 98.4 & -55 \\
\hline AMW & 15 & 221 & 408 & 0.54 & 3.47 & 98.3 & -39 \\
\hline AMW & 17 & 222 & 388 & 0.57 & 3.85 & 98.1 & -35 \\
\hline AMW & 19 & 204 & 388 & 0.53 & 4.16 & 97.9 & \\
\hline AMW & 21 & 203 & 397 & 0.51 & 4.17 & 97.9 & -37 \\
\hline AMW & 23 & 178 & 349 & 0.51 & 5.09 & 97.5 & -49 \\
\hline AMW & 25 & 195 & 346 & 0.56 & 3.02 & 97.1 & -48 \\
\hline AMW & 27 & 204 & 355 & 0.58 & 2.64 & 97.5 & -50 \\
\hline AMW & 29 & 163 & 256 & 0.64 & 3.50 & 96.8 & \\
\hline AMW & 31 & 176 & 314 & 0.56 & 3.19 & 97.1 & -52 \\
\hline AMW & 33 & 201 & 339 & 0.59 & 3.00 & 97.2 & -47 \\
\hline AMW & 35 & 206 & 349 & 0.59 & 3.05 & 97.1 & -50 \\
\hline AMW & 37 & 208 & 350 & 0.60 & 3.26 & 96.9 & \\
\hline AMW & 39 & 204 & 329 & 0.62 & 4.12 & 96.0 & -49 \\
\hline AMW & 41 & 185 & 301 & 0.61 & 5.50 & 94.8 & -52 \\
\hline AMW & 43 & 204 & 346 & 0.59 & 4.05 & 96.3 & -46 \\
\hline AMW & 45 & 241 & 436 & 0.55 & 4.82 & 95.4 & -48 \\
\hline AMW & 47 & 262 & 421 & 0.62 & 4.17 & 95.8 & \\
\hline AMW & 49 & 266 & 437 & 0.61 & 7.64 & 96.1 & -42 \\
\hline AMW & 51 & 72.6 & 120 & 0.61 & 20.9 & 91.0 & -54 \\
\hline AMW & 53 & 92.6 & 159 & 0.58 & 21.0 & 90.4 & -50 \\
\hline AMW & 55 & 8.11 & 17.9 & 0.45 & 58.4 & 62.5 & \\
\hline
\end{tabular}


Table S2. Data matrix, PBDEs (ng/g) in AED+ACL, congener vs depth (cm), AED

\begin{tabular}{|c|c|c|c|c|c|c|c|c|c|c|c|c|c|c|}
\hline PBDE & $0-1$ & $1-2$ & $2-3$ & $3-4$ & $4-5$ & $5-6$ & $6-7$ & $7-8$ & $8-9$ & 9-10 & $10-11$ & $11-12$ & $12-13$ & 13-14 \\
\hline 7 & 0.01 & 0.005 & 0.005 & 0.005 & 0.05 & 0.04 & 0.09 & 0.12 & 0.10 & 0.07 & 0.07 & 0.07 & 0.08 & 0.04 \\
\hline 11 & 0.02 & 0.03 & 0.02 & 0.01 & 0.01 & 0.02 & 0.04 & 0.05 & 0.05 & 0.05 & 0.005 & 0.03 & 0.04 & 0.05 \\
\hline $12+13$ & 0.06 & 0.09 & 0.07 & 0.11 & 0.12 & 0.13 & 0.13 & 0.20 & 0.09 & 0.07 & 0.06 & 0.05 & 0.05 & 0.10 \\
\hline 32 & 0.06 & 0.06 & 0.05 & 0.04 & 0.05 & 0.08 & 0.10 & 0.16 & 0.16 & 0.19 & 0.12 & 0.11 & 0.08 & 0.12 \\
\hline 17 & 0.04 & 0.04 & 0.04 & 0.05 & 0.12 & 0.17 & 0.30 & 0.43 & 0.33 & 0.20 & 0.18 & 0.16 & 0.14 & 0.23 \\
\hline $28 / 33$ & 0.08 & 0.10 & 0.09 & 0.08 & 0.13 & 0.15 & 0.23 & 0.23 & 0.14 & 0.16 & 0.14 & 0.13 & 0.12 & 0.18 \\
\hline 75 & 10.05 & 12.80 & 4.13 & 2.55 & 2.01 & 2.01 & 2.66 & 2.90 & 7.63 & 4.73 & 12.08 & 6.99 & 1.03 & 0.86 \\
\hline 49 & 0.18 & 0.18 & 0.16 & 0.20 & 0.34 & 0.47 & 0.67 & 1.10 & 0.87 & 0.63 & 0.54 & 0.48 & 0.61 & 1.94 \\
\hline 47 & 0.52 & 0.51 & 0.40 & 0.46 & 0.75 & 0.92 & 1.60 & 1.68 & 1.30 & 1.28 & 1.28 & 1.57 & 0.70 & 1.32 \\
\hline 66 & 0.08 & 0.06 & 0.06 & 0.06 & 0.07 & 0.09 & 0.13 & 0.15 & 0.10 & 0.09 & 0.07 & 0.08 & 0.08 & 0.12 \\
\hline 100 & 0.24 & 0.30 & 0.26 & 0.33 & 0.54 & 0.63 & 0.94 & 1.22 & 1.01 & 0.89 & 0.65 & 0.57 & 0.40 & 0.74 \\
\hline 99 & 0.80 & 0.71 & 0.65 & 0.67 & 1.05 & 1.18 & 1.82 & 1.83 & 1.47 & 2.27 & 1.45 & 1.00 & 0.88 & 1.99 \\
\hline $155 / 126$ & 0.99 & 1.20 & 1.23 & 1.64 & 2.70 & 2.88 & 3.74 & 5.76 & 5.50 & 4.86 & 3.73 & 3.01 & 1.62 & 2.25 \\
\hline 154 & 1.85 & 1.96 & 2.26 & 2.72 & 4.67 & 5.24 & 7.38 & 9.74 & 9.45 & 10.47 & 7.13 & 6.42 & 3.86 & 5.19 \\
\hline 153 & 3.37 & 3.08 & 3.68 & 4.80 & 8.34 & 8.65 & 14.97 & 17.35 & 15.49 & 30.07 & 15.08 & 13.92 & 9.73 & 13.73 \\
\hline 138 & 0.82 & 0.92 & 2.01 & 1.38 & 1.66 & 1.46 & 1.95 & 2.32 & 1.85 & 3.36 & 2.31 & 2.19 & 2.02 & 2.65 \\
\hline 183 & 20.03 & 19.79 & 20.67 & 29.31 & 39.84 & 41.86 & 69.42 & 82.75 & 69.64 & 92.42 & 73.71 & 61.74 & 46.70 & 52.30 \\
\hline 202 & 3.77 & 3.67 & 3.06 & 3.11 & 0.43 & 3.95 & 4.78 & 5.28 & 5.71 & 5.45 & 4.88 & 3.80 & 2.52 & 2.98 \\
\hline 201 & 7.06 & 7.49 & 7.09 & 7.70 & 8.51 & 9.60 & 12.59 & 13.40 & 13.44 & 14.47 & 12.28 & 9.74 & 8.80 & 8.78 \\
\hline 204 & 0.93 & 0.85 & 1.00 & 0.82 & 0.88 & 0.98 & 1.18 & 1.35 & 1.11 & 1.33 & 1.23 & 1.10 & 1.30 & 1.23 \\
\hline 197 & 18.00 & 18.76 & 19.57 & 25.89 & 30.94 & 36.90 & 53.84 & 62.22 & 57.93 & 68.06 & 61.24 & 49.21 & 37.53 & 43.77 \\
\hline 203 & 13.02 & 13.32 & 14.98 & 17.63 & 20.60 & 24.10 & 35.92 & 37.08 & 35.32 & 44.46 & 38.02 & 30.74 & 27.72 & 29.36 \\
\hline 196 & 16.76 & 16.38 & 17.95 & 20.74 & 25.03 & 31.01 & 47.14 & 48.00 & 45.32 & 56.01 & 50.52 & 38.87 & 22.35 & 33.51 \\
\hline 194 & 3.56 & 3.47 & 3.04 & 2.80 & 2.71 & 3.00 & 3.34 & 3.18 & 2.95 & 3.64 & 2.63 & 2.30 & 2.19 & 2.36 \\
\hline 195 & 4.03 & 3.62 & 4.51 & 5.35 & 4.92 & 5.23 & 7.50 & 7.17 & 6.41 & 10.07 & 8.12 & 6.49 & 8.91 & 6.79 \\
\hline 208 & 360 & 301 & 281 & 292 & 301 & 306 & 428 & 373 & 265 & 505 & 541 & 392 & 352 & 338 \\
\hline 207 & 571 & 480 & 448 & 471 & 481 & 503 & 714 & 622 & 473 & 832 & 861 & 629 & 575 & 551 \\
\hline 206 & 482 & 446 & 423 & 491 & 594 & 604 & 951 & 785 & 693 & 1138 & 1013 & 674 & 612 & 735 \\
\hline 209 & 34115 & 28668 & 25918 & 26846 & 26722 & 31725 & 46219 & 37978 & 31286 & 52933 & 57193 & 38757 & 36207 & 36959 \\
\hline
\end{tabular}

Nondetects (blue) $=\mathrm{MDL} / 2$ 
Table S2, continued, ACL.

\begin{tabular}{|c|c|c|c|c|c|c|c|c|c|c|c|c|c|c|}
\hline PBDE & $0-1$ & $1-2$ & $2-3$ & $3-4$ & $4-5$ & $5-6$ & $6-7$ & $7-8$ & $8-9$ & $9-10$ & $10-11$ & $11-22$ & $12-13$ & $13-14$ \\
\hline 7 & 0.02 & 0.02 & 0.05 & 0.02 & 0.02 & 0.02 & 0.01 & 0.01 & 0.005 & 0.02 & 0.01 & 0.005 & 0.005 & 0.005 \\
\hline 11 & 0.05 & 0.04 & 0.05 & 0.07 & 0.06 & 0.05 & 0.04 & 0.03 & 0.03 & 0.06 & 0.01 & 0.02 & 0.03 & 0.01 \\
\hline $12+13$ & 0.02 & 0.02 & 0.04 & 0.04 & 0.03 & 0.03 & 0.03 & 0.02 & 0.02 & 0.13 & 0.02 & 0.02 & 0.10 & 0.03 \\
\hline 32 & 0.04 & 0.06 & 0.05 & 0.09 & 0.08 & 0.08 & 0.05 & 0.07 & 0.08 & 0.01 & 0.05 & 0.05 & 0.02 & 0.05 \\
\hline 17 & 0.07 & 0.06 & 0.06 & 0.06 & 0.06 & 0.06 & 0.05 & 0.04 & 0.03 & 0.02 & 0.03 & 0.02 & 0.03 & 0.03 \\
\hline $28 / 33$ & 0.05 & 0.05 & 0.06 & 0.04 & 0.04 & 0.04 & 0.03 & 0.02 & 0.03 & 0.01 & 0.01 & 0.01 & 0.01 & 0.01 \\
\hline 75 & 1.20 & 0.51 & 0.32 & 0.18 & 0.28 & 0.15 & 0.15 & 0.26 & 0.25 & 0.10 & 0.19 & 0.13 & 0.07 & 0.02 \\
\hline 49 & 0.18 & 0.19 & 0.21 & 0.23 & 0.12 & 0.15 & 0.14 & 0.13 & 0.09 & 0.07 & 0.07 & 0.05 & 0.04 & 0.02 \\
\hline 47 & 0.40 & 0.28 & 0.47 & 0.29 & 0.28 & 0.35 & 0.36 & 0.26 & 0.25 & 0.15 & 0.16 & 0.13 & 0.10 & 0.06 \\
\hline 66 & 0.07 & 0.05 & 0.05 & 0.04 & 0.03 & 0.03 & 0.03 & 0.03 & 0.03 & 0.01 & 0.02 & 0.01 & 0.005 & 0.005 \\
\hline 100 & 0.13 & 0.09 & 0.22 & 0.08 & 0.07 & 0.09 & 0.09 & 0.07 & 0.03 & 0.04 & 0.04 & 0.03 & 0.03 & 0.03 \\
\hline 99 & 0.19 & 0.10 & 0.50 & 0.08 & 0.12 & 0.22 & 0.19 & 0.16 & 0.09 & 0.08 & 0.06 & 0.06 & 0.04 & 0.05 \\
\hline $155 / 126$ & 0.20 & 0.15 & 0.14 & 0.12 & 0.12 & 0.12 & 0.11 & 0.08 & 0.06 & 0.06 & 0.05 & 0.005 & 0.02 & 0.01 \\
\hline 154 & 0.29 & 0.23 & 0.24 & 0.18 & 0.16 & 0.18 & 0.16 & 0.16 & 0.11 & 0.09 & 0.08 & 0.05 & 0.01 & 0.01 \\
\hline 153 & 0.45 & 0.37 & 0.36 & 0.14 & 0.21 & 0.48 & 0.38 & 0.63 & 0.20 & 0.25 & 0.31 & 0.3 & 0.04 & 0.02 \\
\hline 138 & 0.07 & 0.02 & 0.005 & 0.04 & 0.02 & 0.04 & 0.03 & 0.16 & 0.18 & 0.06 & 0.07 & 0.05 & 0.01 & 0.005 \\
\hline 183 & 4.98 & 1.95 & 1.61 & 1.33 & 1.28 & 2.68 & 2.14 & 4.47 & 1.59 & 1.57 & 2.05 & 1.61 & 0.17 & 0.03 \\
\hline 202 & 0.37 & 0.26 & 0.28 & 0.29 & 0.26 & 0.26 & 0.26 & 0.24 & 0.31 & 0.20 & 0.14 & 0.07 & 0.07 & 0.01 \\
\hline 201 & 0.87 & 0.44 & 0.47 & 0.55 & 0.41 & 0.38 & 0.41 & 0.64 & 0.77 & 0.48 & 0.34 & 0.26 & 0.12 & 0.03 \\
\hline 204 & 0.21 & 0.23 & 0.27 & 0.28 & 0.21 & 0.075 & 0.21 & 0.53 & 0.41 & 0.25 & 0.18 & 0.15 & 0.25 & 0.075 \\
\hline 197 & 1.97 & 1.49 & 1.39 & 0.80 & 0.74 & 2.15 & 1.54 & 3.28 & 1.47 & 1.53 & 0.78 & 1.11 & 0.23 & 0.08 \\
\hline 203 & 1.69 & 0.82 & 0.95 & 0.92 & 0.83 & 0.95 & 0.91 & 1.71 & 1.75 & 1.15 & 0.87 & 0.74 & 0.24 & 0.05 \\
\hline 196 & 1.87 & 1.10 & 1.10 & 1.16 & 1.07 & 1.22 & 1.18 & 1.86 & 1.52 & 1.18 & 0.89 & 0.84 & 0.33 & 0.10 \\
\hline 194 & 0.99 & 0.35 & 0.38 & 0.18 & 0.11 & 0.11 & 0.14 & 0.27 & 0.38 & 0.30 & 0.11 & 0.10 & 0.06 & 0.03 \\
\hline 195 & 0.85 & 0.63 & 0.69 & 0.75 & 0.67 & 0.65 & 0.81 & 0.77 & 0.74 & 0.57 & 0.53 & 0.34 & 0.25 & 0.09 \\
\hline 208 & 18.54 & 10.65 & 15.24 & 15.08 & 12.06 & 10.92 & 13.58 & 17.85 & 24.57 & 19.44 & 12.71 & 9.70 & 4.49 & 1.12 \\
\hline 207 & 31.18 & 18.97 & 26.32 & 26.04 & 20.79 & 19.40 & 23.73 & 31.36 & 40.83 & 33.70 & 21.96 & 16.49 & 7.12 & 1.74 \\
\hline 206 & 35.90 & 29.50 & 38.55 & 32.07 & 30.13 & 29.91 & 33.90 & 37.70 & 52.13 & 47.08 & 29.34 & 20.89 & 8.35 & 1.97 \\
\hline 209 & 2396 & 2516 & 2340 & 2731 & 2858 & 3020 & 3311 & 1924 & 2339 & 2580 & 2334 & 1303 & 853 & 240 \\
\hline
\end{tabular}


Table S3. Data matrix, PBDEs (ng/g) in AMW, congener vs depth $(\mathrm{cm})$

\begin{tabular}{|c|c|c|c|c|c|c|c|c|c|c|}
\hline PBDE & $0-2$ & $2-4$ & $4-6$ & $6-8$ & 8-10 & $10-12$ & $12-14$ & $14-16$ & $16-18$ & $18-20$ \\
\hline 10 & 0.93 & 0.89 & 0.75 & 0.80 & 1.63 & 1.43 & 1.51 & 2.03 & 3.02 & 4.75 \\
\hline 7 & 2.79 & 3.56 & 3.77 & 4.00 & 4.08 & 3.57 & 6.04 & 6.10 & 6.04 & 5.42 \\
\hline 11 & 2.79 & 2.67 & 2.26 & 2.40 & 2.45 & 2.14 & 0.75 & 1.36 & 3.02 & 2.71 \\
\hline 8 & 4.65 & 4.44 & 5.28 & 5.60 & 4.90 & 4.29 & 5.28 & 6.10 & 6.04 & 5.42 \\
\hline $12+13$ & 1.86 & 1.78 & 2.26 & 2.40 & 3.27 & 2.86 & 3.02 & 3.39 & 3.77 & 3.39 \\
\hline 15 & 2.79 & 3.56 & 3.77 & 4.00 & 4.08 & 3.57 & 3.77 & 5.42 & 4.53 & 4.07 \\
\hline 32 & 0.93 & 0.89 & 0.75 & 0.80 & 0.82 & 1.43 & 1.51 & 2.03 & 2.26 & 2.71 \\
\hline 17 & 29.77 & 32.89 & 32.45 & 32.00 & 34.29 & 29.29 & 31.70 & 33.90 & 33.96 & 35.93 \\
\hline 25 & 19.53 & 21.33 & 21.89 & 23.20 & 26.12 & 21.43 & 24.15 & 25.08 & 24.91 & 27.12 \\
\hline $28 / 33$ & 9.30 & 15.11 & 16.60 & 17.60 & 17.14 & 12.14 & 13.58 & 16.27 & 15.85 & 14.92 \\
\hline 35 & 0.04 & 0.89 & 0.75 & 0.80 & 0.82 & 0.71 & 1.51 & 1.36 & 1.51 & 2.03 \\
\hline 37 & 1.86 & 2.67 & 2.26 & 2.40 & 2.45 & 1.43 & 1.51 & 2.03 & 2.26 & 2.03 \\
\hline 75 & 37.21 & 10.67 & 9.06 & 16.00 & 12.24 & 7.86 & 8.30 & 6.10 & 9.81 & 8.14 \\
\hline 49 & 69.77 & 79.11 & 86.79 & 97.60 & 106.94 & 94.29 & 98.87 & 97.63 & 86.04 & 95.59 \\
\hline 71 & 5.58 & 6.22 & 3.77 & 3.20 & 3.27 & 4.29 & 3.02 & 2.03 & 2.26 & 2.03 \\
\hline 47 & 199.07 & 222.22 & 220.38 & 218.40 & 217.14 & 165.71 & 147.17 & 161.36 & 181.89 & 211.53 \\
\hline 66 & 11.16 & 13.33 & 13.58 & 14.40 & 14.69 & 10.71 & 9.06 & 10.85 & 15.09 & 19.66 \\
\hline 77 & 0.93 & 1.78 & 1.51 & 0.80 & 1.63 & 1.43 & 1.51 & 1.36 & 2.26 & 2.71 \\
\hline 100 & 41.86 & 43.56 & 40.75 & 36.80 & 31.02 & 19.29 & 12.83 & 10.85 & 12.08 & 15.59 \\
\hline 119 & 0.93 & 1.78 & 0.75 & 0.80 & 3.27 & 0.34 & 0.34 & 0.68 & 0.75 & 0.68 \\
\hline 99 & 188.84 & 192.89 & 182.64 & 168.80 & 150.20 & 106.43 & 85.28 & 88.81 & 92.83 & 113.90 \\
\hline 85 & 4.65 & 4.44 & 3.02 & 2.40 & 2.45 & 1.43 & 1.51 & 0.68 & 0.75 & 0.68 \\
\hline $155 / 126$ & 8.37 & 9.78 & 9.06 & 10.40 & 12.24 & 12.86 & 12.08 & 14.24 & 17.36 & 24.41 \\
\hline 154 & 36.28 & 36.44 & 36.98 & 39.20 & 41.63 & 38.57 & 35.47 & 42.03 & 50.57 & 62.37 \\
\hline 153 & 36.28 & 34.67 & 36.23 & 37.60 & 38.37 & 32.14 & 29.43 & 31.19 & 33.96 & 37.29 \\
\hline 138 & 5.58 & 4.44 & 3.77 & 4.00 & 4.08 & 4.29 & 3.77 & 4.07 & 3.77 & 5.42 \\
\hline 183 & 19.53 & 22.22 & 30.19 & 37.60 & 39.18 & 33.57 & 31.70 & 26.44 & 51.32 & 33.90 \\
\hline 181 & 4.65 & 7.11 & 4.53 & 7.20 & 3.27 & 6.43 & 3.77 & 3.39 & 3.77 & 3.39 \\
\hline 202 & 9.30 & 8.89 & 8.30 & 10.40 & 10.61 & 11.43 & 10.57 & 10.17 & 11.32 & 11.53 \\
\hline 201 & 20.47 & 19.56 & 20.38 & 23.20 & 24.49 & 27.86 & 26.42 & 27.12 & 30.19 & 31.86 \\
\hline 204 & 13.95 & 3.56 & 1.51 & 2.40 & 21.22 & 2.86 & 3.02 & 25.08 & 2.26 & 33.90 \\
\hline 197 & 31.63 & 30.22 & 33.21 & 41.60 & 44.90 & 44.29 & 45.28 & 51.53 & 61.89 & 70.51 \\
\hline 203 & 18.60 & 21.33 & 17.36 & 25.60 & 25.31 & 27.86 & 24.91 & 27.80 & 33.21 & 35.93 \\
\hline 196 & 18.60 & 20.44 & 21.89 & 24.80 & 26.12 & 26.43 & 24.15 & 28.47 & 33.21 & 35.25 \\
\hline 194 & 26.05 & 32.89 & 33.21 & 37.60 & 39.18 & 38.57 & 36.23 & 39.32 & 43.02 & 33.22 \\
\hline 195 & 16.74 & 15.11 & 16.60 & 20.80 & 15.51 & 23.57 & 20.38 & 20.34 & 26.42 & 23.73 \\
\hline 208 & 118 & 119 & 144 & 153 & 168 & 186 & 172 & 202 & 226 & 215 \\
\hline 207 & 152 & 160 & 193 & 206 & 229 & 246 & 235 & 287 & 315 & 309 \\
\hline 206 & 110 & 131 & 176 & 193 & 227 & 224 & 232 & 331 & 341 & 361 \\
\hline 209 & 5666 & 7055 & 10418 & 10414 & 12824 & 11806 & 13264 & 17026 & 17732 & 19141 \\
\hline
\end{tabular}


Table S3, continued.

\begin{tabular}{|c|c|c|c|c|c|c|c|c|c|c|}
\hline PBDE & $20-22$ & $22-24$ & $24-26$ & $26-28$ & $28-30$ & $30-32$ & $32-34$ & $34-36$ & $36-38$ & $38-40$ \\
\hline 10 & 6.67 & 10.18 & 7.55 & 7.50 & 8.45 & 9.85 & 9.18 & 7.50 & 6.67 & 4.38 \\
\hline 7 & 5.00 & 3.64 & 6.04 & 5.36 & 6.76 & 9.85 & 13.11 & 16.25 & 7.18 & 8.22 \\
\hline 11 & 1.67 & 1.45 & 1.51 & 1.43 & 1.69 & 2.46 & 2.62 & 2.50 & 1.03 & 1.10 \\
\hline 8 & 5.00 & 3.64 & 6.04 & 3.57 & 2.82 & 4.92 & 3.93 & 5.00 & 2.05 & 2.19 \\
\hline $12+13$ & 4.17 & 3.64 & 3.77 & 3.57 & 1.69 & 2.46 & 2.62 & 2.50 & 1.03 & 1.64 \\
\hline 15 & 4.17 & 4.36 & 6.04 & 5.36 & 3.94 & 6.15 & 3.93 & 6.25 & 3.08 & 3.29 \\
\hline 32 & 3.33 & 4.36 & 3.77 & 2.86 & 2.82 & 6.15 & 6.56 & 7.50 & 5.13 & 4.38 \\
\hline 17 & 41.67 & 52.36 & 43.77 & 27.14 & 15.77 & 19.69 & 17.05 & 15.00 & 8.21 & 7.67 \\
\hline 25 & 31.67 & 34.91 & 30.19 & 20.36 & 11.83 & 14.77 & 11.80 & 10.00 & 5.13 & 5.48 \\
\hline $28 / 33$ & 15.00 & 13.82 & 15.85 & 16.07 & 14.08 & 16.00 & 14.43 & 12.50 & 8.21 & 8.22 \\
\hline 35 & 2.50 & 1.45 & 1.51 & 2.14 & 1.69 & 2.46 & 1.31 & 1.25 & 1.03 & 1.10 \\
\hline 37 & 2.50 & 1.45 & 1.51 & 1.43 & 1.13 & 1.23 & 1.31 & 1.25 & 1.54 & 1.64 \\
\hline 75 & 5.00 & 3.64 & 5.28 & 7.14 & 2.82 & 3.69 & 3.93 & 3.75 & 2.05 & 2.19 \\
\hline 49 & 119.17 & 150.55 & 119.25 & 83.57 & 51.27 & 61.54 & 55.08 & 61.25 & 34.36 & 41.10 \\
\hline 71 & 2.50 & 2.91 & 2.26 & 2.86 & 2.25 & 4.92 & 3.93 & 2.50 & 2.05 & 2.74 \\
\hline 47 & 246.67 & 317.82 & 225.66 & 192.50 & 154.37 & 171.08 & 137.70 & 112.50 & 72.82 & 72.88 \\
\hline 66 & 22.50 & 24.73 & 17.36 & 22.50 & 21.41 & 23.38 & 17.05 & 12.50 & 9.23 & 8.77 \\
\hline 77 & 2.5 & 2.18 & 2.26 & 2.14 & 1.69 & 2.46 & 1.31 & 2.50 & 1.54 & 2.19 \\
\hline 100 & 20.00 & 38.55 & 21.13 & 28.93 & 37.18 & 40.62 & 38.03 & 35.00 & 24.10 & 22.47 \\
\hline 119 & 0.83 & 1.45 & 0.75 & 1.43 & 2.25 & 2.46 & 2.62 & 5.00 & 3.08 & 3.29 \\
\hline 99 & 135.00 & 235.64 & 141.89 & 163.21 & 175.77 & 179.69 & 152.13 & 132.50 & 107.18 & 104.66 \\
\hline 85 & 0.83 & 0.73 & 1.51 & 0.71 & 1.13 & 1.23 & 0.08 & 2.50 & 1.03 & 1.64 \\
\hline $155 / 126$ & 31.67 & 49.45 & 30.19 & 36.43 & 51.83 & 61.54 & 61.64 & 78.75 & 55.90 & 63.01 \\
\hline 154 & 71.67 & 90.91 & 64.91 & 75.36 & 98.03 & 116.92 & 135.08 & 191.25 & 140.51 & 174.25 \\
\hline 153 & 42.50 & 58.18 & 38.49 & 41.79 & 51.27 & 66.46 & 102.30 & 222.50 & 171.79 & 210.41 \\
\hline 138 & 6.67 & 8.73 & 6.04 & 5.71 & 6.76 & 7.38 & 7.87 & 16.25 & 9.74 & 10.96 \\
\hline 183 & 51.67 & 84.36 & 41.51 & 57.14 & 135.77 & 203.08 & 403.93 & 1008.75 & 800.51 & 920.00 \\
\hline 181 & 3.33 & 2.91 & 3.77 & 3.57 & 1.69 & 2.46 & 0.04 & 0.04 & 0.51 & 1.10 \\
\hline 202 & 10.83 & 11.64 & 12.08 & 10.36 & 14.08 & 16.00 & 17.05 & 22.50 & 20.00 & 22.47 \\
\hline 201 & 33.33 & 40.00 & 36.23 & 39.29 & 56.34 & 54.15 & 60.33 & 86.25 & 73.85 & 78.90 \\
\hline 204 & 3.33 & 2.91 & 3.02 & 3.21 & 5.07 & 0.755 & 3.93 & 6.25 & 5.64 & 7.12 \\
\hline 197 & 75.00 & 79.27 & 68.68 & 76.79 & 145.35 & 188.31 & 300.33 & 637.50 & 433.85 & 506.85 \\
\hline 203 & 38.33 & 45.82 & 39.25 & 50.71 & 93.52 & 89.85 & 125.90 & 232.50 & 182.05 & 203.29 \\
\hline 196 & 35.00 & 47.27 & 35.47 & 46.43 & 96.90 & 104.62 & 156.07 & 312.50 & 234.87 & 266.30 \\
\hline 194 & 37.50 & 40.00 & 42.26 & 36.43 & 39.44 & 23.38 & 20.98 & 20.00 & 30.77 & 24.66 \\
\hline 195 & 29.17 & 40.00 & 31.70 & 41.43 & 57.46 & 25.85 & 17.05 & 32.50 & 49.23 & 53.70 \\
\hline 208 & 233 & 315 & 251 & 337 & 570 & 326 & 262 & 376 & 430 & 438 \\
\hline 207 & 327 & 444 & 344 & 483 & 887 & 539 & 483 & 803 & 776 & 826 \\
\hline 206 & 402 & 577 & 424 & 671 & 1301 & 886 & 741 & 930 & 799 & 751 \\
\hline 209 & 22098 & 28754 & 21607 & 29545 & 32647 & 48481 & 33186 & 43209 & 30005 & 29738 \\
\hline
\end{tabular}


Table S3. continued.

\begin{tabular}{|c|c|c|c|c|c|c|}
\hline PBDE & $40-42$ & $42-44$ & $44-46$ & $46-48$ & $48-50$ & $50-52$ \\
\hline 10 & 3.08 & 1.71 & 1.13 & 1.05 & 0.27 & 0.08 \\
\hline 7 & 7.18 & 1.14 & 1.13 & 1.05 & 0.38 & 0.15 \\
\hline 11 & 1.03 & 0.005 & 1.69 & 1.58 & 0.27 & 0.23 \\
\hline 8 & 1.03 & 1.71 & 2.25 & 1.58 & 0.49 & 0.54 \\
\hline $12+13$ & 1.03 & 1.71 & 1.69 & 1.58 & 0.71 & 0.69 \\
\hline 15 & 3.08 & 3.43 & 3.94 & 3.16 & 1.70 & 1.38 \\
\hline 32 & 3.59 & 2.29 & 1.69 & 1.58 & 0.33 & 0.31 \\
\hline 17 & 6.67 & 4.00 & 2.25 & 2.11 & 0.88 & 0.54 \\
\hline 25 & 1.54 & 2.86 & 1.69 & 1.05 & 0.49 & 0.38 \\
\hline $28 / 33$ & 6.15 & 5.71 & 3.38 & 3.16 & 0.60 & 0.31 \\
\hline 35 & 1.03 & 1.14 & 0.56 & 1.05 & 0.05 & 0.08 \\
\hline 37 & 2.05 & 2.86 & 1.69 & 2.11 & 0.22 & 0.15 \\
\hline 75 & 1.54 & 1.14 & 1.13 & 1.05 & 0.16 & 0.23 \\
\hline 49 & 32.82 & 21.71 & 14.65 & 11.58 & 2.63 & 1.54 \\
\hline 71 & 2.56 & 2.29 & 2.25 & 1.05 & 0.38 & 0.23 \\
\hline 47 & 62.05 & 45.14 & 25.92 & 20.00 & 5.21 & 3.77 \\
\hline 66 & 7.18 & 6.29 & 3.38 & 3.16 & 0.66 & 0.38 \\
\hline 77 & 2.05 & 1.71 & 1.13 & 1.05 & 0.11 & 0.055 \\
\hline 100 & 17.95 & 8.57 & 4.51 & 3.68 & 0.88 & 0.69 \\
\hline 119 & 3.08 & 1.71 & 1.13 & 1.58 & 0.93 & 0.69 \\
\hline 99 & 94.36 & 67.43 & 33.80 & 24.74 & 5.59 & 3.31 \\
\hline 85 & 1.54 & 21.71 & 0.56 & 2.11 & 0.16 & 0.31 \\
\hline $155 / 126$ & 59.49 & 33.14 & 16.34 & 15.79 & 1.53 & 0.69 \\
\hline 154 & 157.95 & 71.43 & 27.61 & 20.53 & 8.44 & 6.38 \\
\hline 153 & 178.97 & 83.43 & 25.35 & 14.74 & 4.16 & 1.31 \\
\hline 138 & 7.69 & 4.57 & 2.25 & 1.58 & 0.075 & 0.15 \\
\hline 183 & 771.28 & 336.00 & 101.41 & 29.47 & 12.71 & 3.69 \\
\hline 181 & 2.56 & 2.29 & 4.51 & 2.11 & 0.33 & 0.15 \\
\hline 202 & 19.49 & 17.71 & 11.27 & 14.21 & 1.81 & 0.62 \\
\hline 201 & 65.13 & 52.00 & 28.73 & 29.47 & 5.59 & 1.62 \\
\hline 204 & 0.755 & 0.755 & 47.89 & 25.26 & 0.755 & 0.755 \\
\hline 197 & 426.15 & 242.86 & 99.72 & 50.00 & 15.07 & 4.15 \\
\hline 203 & 164.10 & 105.71 & 50.70 & 42.63 & 7.12 & 2.54 \\
\hline 196 & 216.41 & 128.00 & 55.21 & 39.47 & 8.44 & 2.77 \\
\hline 194 & 20.51 & 17.71 & 4.51 & 4.74 & 1.53 & 0.54 \\
\hline 195 & 26.67 & 34.29 & 14.65 & 14.74 & 3.78 & 0.62 \\
\hline 208 & 315 & 301 & 145 & 166 & 33 & 10 \\
\hline 207 & 616 & 461 & 207 & 215 & 47 & 14 \\
\hline 206 & 614 & 393 & 205 & 217 & 35 & 10 \\
\hline 209 & 23677 & 16862 & 9007 & 10060 & 1217 & 397 \\
\hline
\end{tabular}


Table S4. CODs, d.f.s, and Q for AED+ACL run with EPA-PMF

\begin{tabular}{|c|c|c|c|c|c|c|c|c|c|c|c|}
\hline \multirow{2}{*}{$\begin{array}{l}\text { No. of } \\
\text { Factors }\end{array}$} & \multicolumn{11}{|c|}{ Coefficient of Determination $\left(R^{\wedge} 2\right)$} \\
\hline & 7 & 11 & $12+13$ & 32 & 17 & $28 / 33$ & 75 & 49 & 47 & 66 & 100 \\
\hline 2 & 0.82 & 0.58 & 0.32 & 0.74 & 0.87 & 0.91 & 0.28 & 0.61 & 0.93 & 0.85 & 0.91 \\
\hline 3 & 0.88 & 0.60 & 0.32 & 0.69 & 0.93 & 0.92 & 0.54 & 0.65 & 0.94 & 0.89 & 0.96 \\
\hline 4 & 0.86 & 0.67 & 0.36 & 0.75 & 0.94 & 0.94 & 0.91 & 0.65 & 0.93 & 0.90 & 0.96 \\
\hline No. of & \multicolumn{11}{|c|}{ Coefficient of Determination $\left(R^{\wedge} \mathbf{2}\right)$} \\
\hline Factors & 99 & $155 / 126$ & 154 & 153 & 138 & 183 & 202 & 201 & 204 & 197 & 203 \\
\hline 2 & 0.92 & 0.89 & 0.94 & 0.90 & 0.91 & 0.98 & 0.85 & 0.96 & 0.85 & 0.99 & 0.99 \\
\hline 3 & 0.93 & 0.94 & 0.98 & 0.91 & 0.91 & 0.99 & 0.85 & 0.98 & 0.90 & 0.99 & 0.99 \\
\hline 4 & 0.93 & 0.96 & 0.98 & 0.92 & 0.94 & 0.99 & 0.93 & 0.99 & 0.94 & 0.99 & 0.99 \\
\hline \multicolumn{12}{|c|}{ Coefficient of Determination $\left(R^{\wedge} \mathbf{2}\right)$} \\
\hline Factors & 196 & 194 & 195 & 208 & 207 & 206 & 209 & & d.f. & $Q$ value & $Q($ true $) / Q(\exp )$ \\
\hline 2 & 0.99 & 0.73 & 0.93 & 0.90 & 0.92 & 0.98 & 0.92 & & 755 & 783.53 & 1.12 \\
\hline 3 & 0.99 & 0.89 & 0.92 & 0.95 & 0.96 & 0.98 & 0.96 & & 698 & 470.25 & 0.73 \\
\hline 4 & 0.99 & 0.94 & 0.95 & 0.98 & 0.99 & 0.99 & 0.97 & & 641 & 313.78 & 0.54 \\
\hline
\end{tabular}


Table S5. CODs, d.f.s, and Q for AED+ACL run with B-PMF

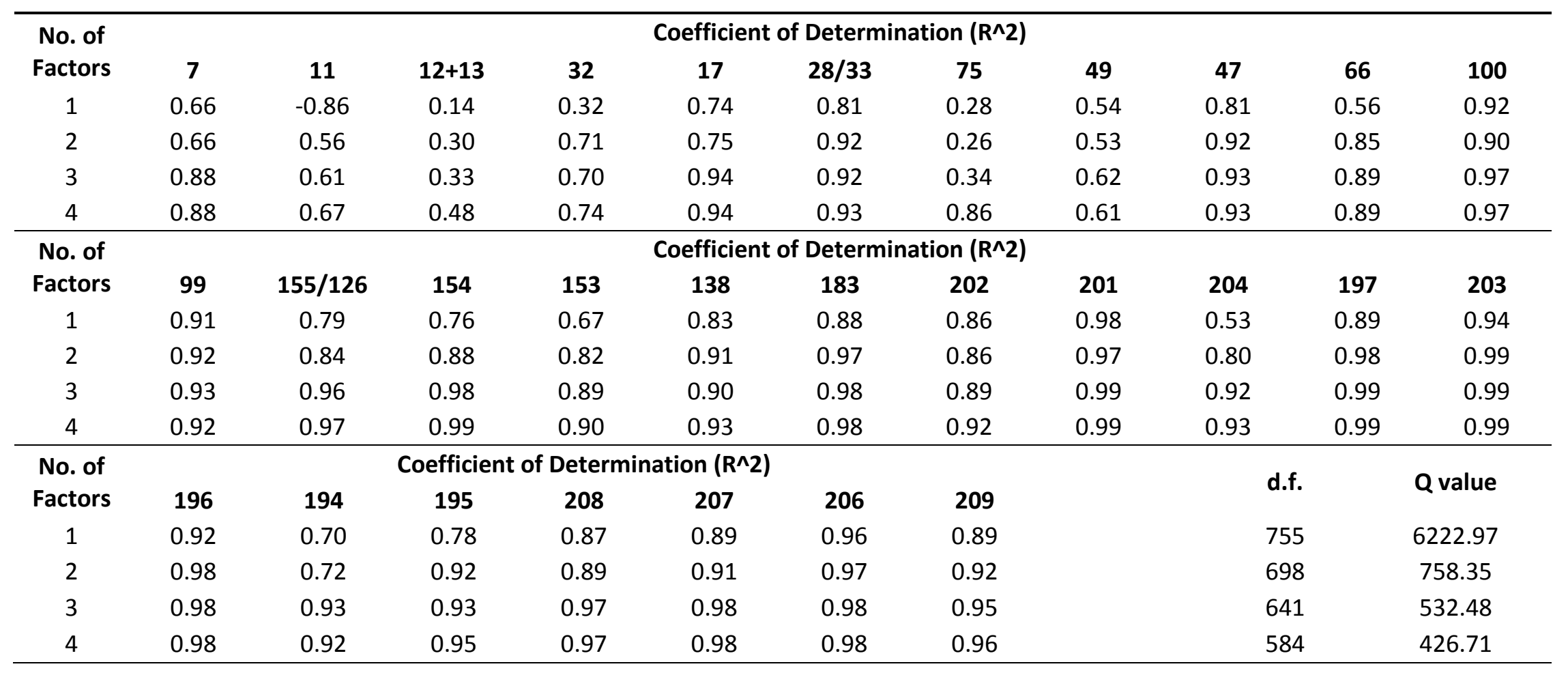


Table S6. CODs, d.f.s, and Q for AMW run with EPA-PMF

\begin{tabular}{|c|c|c|c|c|c|c|c|c|c|c|c|}
\hline \multirow{2}{*}{$\begin{array}{l}\text { No. of } \\
\text { Factors }\end{array}$} & \multicolumn{11}{|c|}{ Coefficient of Determination $\left(R^{\wedge} \mathbf{2}\right)$} \\
\hline & 10 & 7 & 11 & 8 & $12+13$ & 15 & 32 & 17 & 25 & $28 / 33$ & 35 \\
\hline 3 & 0.59 & 0.27 & 0.33 & 0.67 & 0.79 & 0.41 & 0.81 & 0.90 & 0.92 & 0.82 & 0.55 \\
\hline 4 & 0.68 & 0.28 & 0.33 & 0.67 & 0.86 & 0.58 & 0.83 & 0.86 & 0.89 & 0.84 & 0.73 \\
\hline 5 & 0.80 & 0.77 & 0.58 & 0.73 & 0.89 & 0.58 & 0.94 & 0.85 & 0.90 & 0.87 & 0.74 \\
\hline 6 & 0.95 & 0.85 & 0.60 & 0.82 & 0.87 & 0.57 & 0.86 & 0.86 & 0.91 & 0.91 & 0.78 \\
\hline No. of & \multicolumn{11}{|c|}{ Coefficient of Determination $\left(R^{\wedge} \mathbf{2}\right)$} \\
\hline Factors & 37 & 75 & 49 & 71 & 47 & 66 & 77 & 100 & 119 & 99 & 85 \\
\hline 3 & 0.13 & 0.32 & 0.88 & 0.58 & 0.86 & 0.68 & 0.63 & 0.49 & 0.74 & 0.65 & 0.00 \\
\hline 4 & 0.22 & 0.39 & 0.83 & 0.53 & 0.91 & 0.81 & 0.71 & 0.65 & 0.74 & 0.73 & 0.00 \\
\hline 5 & 0.55 & 0.61 & 0.85 & 0.62 & 0.90 & 0.83 & 0.77 & 0.86 & 0.78 & 0.79 & 0.08 \\
\hline 6 & 0.64 & 0.58 & 0.84 & 0.69 & 0.89 & 0.94 & 0.76 & 0.94 & 0.77 & 0.90 & 0.15 \\
\hline No. of & \multicolumn{11}{|c|}{ Coefficient of Determination $\left(R^{\wedge} 2\right)$} \\
\hline Factors & $155 / 126$ & 154 & 153 & 138 & 183 & 181 & 202 & 201 & 204 & 197 & 203 \\
\hline 3 & 0.93 & 0.97 & 0.86 & 0.89 & 0.88 & 0.66 & 0.77 & 0.97 & 0.02 & 0.93 & 0.97 \\
\hline 4 & 0.90 & 0.97 & 0.96 & 0.89 & 0.96 & 0.68 & 0.85 & 0.96 & 0.83 & 0.98 & 0.99 \\
\hline 5 & 0.95 & 0.97 & 0.93 & 0.88 & 0.92 & 0.74 & 0.92 & 0.98 & 0.81 & 0.94 & 0.98 \\
\hline 6 & 0.98 & 0.98 & 0.98 & 0.92 & 0.99 & 0.74 & 0.9 & 0.97 & 0.94 & 0.99 & 0.99 \\
\hline No. of & \multicolumn{7}{|c|}{ Coefficient of Determination ( $\left.\mathrm{R}^{\wedge} \mathbf{2}\right)$} & $d f$ & O value & \multirow{2}{*}{\multicolumn{2}{|c|}{$Q($ true $) / Q(\exp )$}} \\
\hline Factors & 196 & 194 & 195 & 208 & 207 & 206 & 209 & d.t. & Q value & & \\
\hline 3 & 0.95 & 0.81 & 0.50 & 0.70 & 0.87 & 0.73 & 0.80 & 842 & 1379 & \multicolumn{2}{|c|}{1.597447} \\
\hline 4 & 0.99 & 0.76 & 0.46 & 0.65 & 0.83 & 0.68 & 0.83 & 776 & 992 & \multicolumn{2}{|c|}{1.227973} \\
\hline 5 & 0.96 & 0.84 & 0.54 & 0.68 & 0.84 & 0.76 & 0.90 & 710 & 656 & \multicolumn{2}{|c|}{0.923642} \\
\hline 6 & 1.00 & 0.84 & 0.64 & 0.80 & 0.87 & 0.84 & 0.95 & 644 & 460 & \multicolumn{2}{|c|}{0.714443} \\
\hline
\end{tabular}


Table S7. CODs, d.f.s, and Q for AMW run with B-PMF

\begin{tabular}{|c|c|c|c|c|c|c|c|c|c|c|c|}
\hline \multirow{2}{*}{$\begin{array}{l}\text { No. of } \\
\text { Factors }\end{array}$} & \multicolumn{11}{|c|}{ Coefficient of Determination $\left(R^{\wedge} 2\right)$} \\
\hline & 10 & 7 & 11 & 8 & $12+13$ & 15 & 32 & 17 & 25 & $28 / 33$ & BDE35 \\
\hline 3 & 0.71 & 0.62 & 0.29 & 0.70 & 0.60 & 0.22 & 0.86 & 0.89 & 0.91 & 0.88 & 0.43 \\
\hline 4 & 0.94 & 0.68 & 0.35 & 0.68 & 0.64 & 0.54 & 0.87 & 0.84 & 0.87 & 0.86 & 0.71 \\
\hline 5 & 0.93 & 0.70 & 0.40 & 0.75 & 0.87 & 0.57 & 0.86 & 0.88 & 0.92 & 0.90 & 0.79 \\
\hline 6 & 0.94 & 0.74 & 0.55 & 0.80 & 0.89 & 0.58 & 0.88 & 0.91 & 0.95 & 0.90 & 0.80 \\
\hline No. of & \multicolumn{11}{|c|}{ Coefficient of Determination $\left(R^{\wedge} 2\right)$} \\
\hline Factors & 37 & 75 & 49 & 71 & 47 & 66 & BFE77 & 100 & 119 & 99 & BDE85 \\
\hline 3 & 0.28 & 0.28 & 0.86 & 0.40 & 0.90 & 0.79 & 0.55 & 0.38 & 0.69 & 0.62 & 0.06 \\
\hline 4 & 0.53 & 0.45 & 0.80 & 0.41 & 0.92 & 0.92 & 0.66 & 0.52 & 0.69 & 0.72 & 0.04 \\
\hline 5 & 0.62 & 0.54 & 0.86 & 0.70 & 0.91 & 0.93 & 0.75 & 0.92 & 0.74 & 0.89 & 0.04 \\
\hline 6 & 0.64 & 0.52 & 0.89 & 0.74 & 0.91 & 0.93 & 0.76 & 0.95 & 0.77 & 0.91 & 0.08 \\
\hline No. of & \multicolumn{11}{|c|}{ Coefficient of Determination $\left(R^{\wedge} 2\right)$} \\
\hline Factors & $155 / 126$ & 154 & 153 & 138 & 183 & 181 & 202 & 201 & 204 & 197 & BDE203 \\
\hline 3 & 0.95 & 0.92 & 0.64 & 0.82 & 0.50 & 0.64 & 0.78 & 0.95 & -0.05 & 0.81 & 0.94 \\
\hline 4 & 0.96 & 0.98 & 0.99 & 0.93 & 0.99 & 0.79 & 0.91 & 0.98 & -0.06 & 0.99 & 0.99 \\
\hline 5 & 0.98 & 0.98 & 0.98 & 0.92 & 0.99 & 0.76 & 0.91 & 0.98 & 0.14 & 0.99 & 0.99 \\
\hline 6 & 0.98 & 0.98 & 0.99 & 0.92 & 1.00 & 0.78 & 0.91 & 0.98 & 0.95 & 0.99 & 0.99 \\
\hline No. of & \multicolumn{8}{|c|}{ Coefficient of Determination $\left(R^{\wedge} 2\right)$} & \multirow{2}{*}{ d.f. } & \multirow{2}{*}{\multicolumn{2}{|c|}{$Q$ value }} \\
\hline Factors & 196 & 194 & 195 & 208 & 207 & 206 & 209 & & & & \\
\hline 3 & 0.87 & 0.78 & 0.47 & 0.66 & 0.85 & 0.78 & 0.87 & & 842 & & 960.59 \\
\hline 4 & 0.99 & 0.71 & 0.54 & 0.77 & 0.87 & 0.83 & 0.92 & & 776 & & 703.06 \\
\hline 5 & 0.99 & 0.78 & 0.54 & 0.75 & 0.86 & 0.85 & 0.93 & & 710 & & 557.89 \\
\hline 6 & 0.99 & 0.83 & 0.61 & 0.80 & 0.88 & 0.85 & 0.93 & & 644 & & 391.70 \\
\hline
\end{tabular}




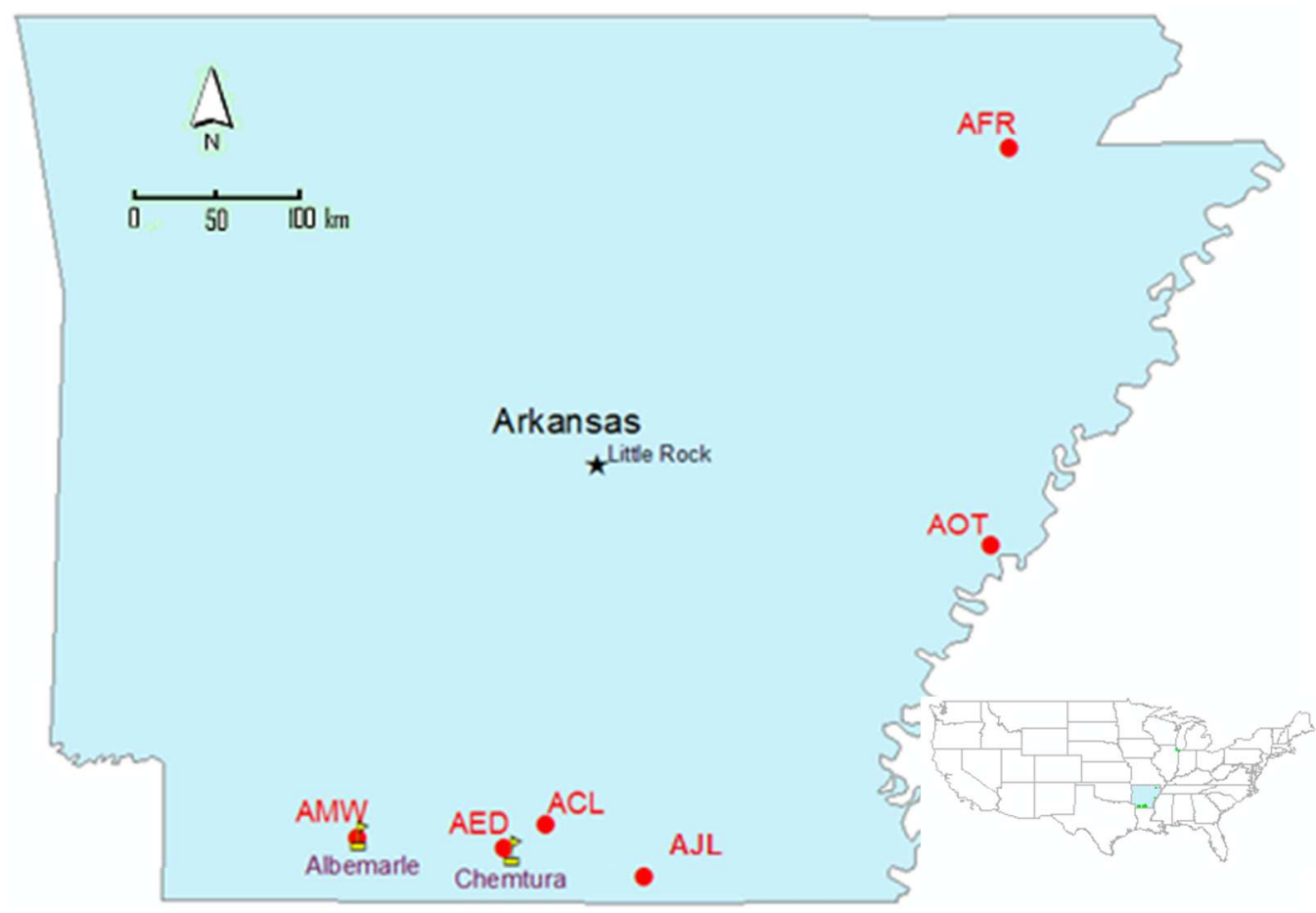

Figure S1. Sampling locations, including Manufacturing plants, Albemarle, Chemtura (Wei et al. 2012).

\begin{tabular}{cccccc}
\hline ID & Sampling Site & Latitude & Longitude & $\begin{array}{c}\text { Distance to } \\
\text { Chemtura } \\
(\mathbf{G L C}) \mathbf{( k m )}\end{array}$ & $\begin{array}{c}\text { Distance to } \\
\text { Albemarle } \\
(\mathbf{k m})\end{array}$ \\
\hline AED & West Lake of El Dorado & 33.2223 & -92.6966 & 7.19 & 57.71 \\
ACL & Calion Lake & 33.3186 & -92.5331 & 25.76 & 73.04 \\
AJL & Lake Jack Lee & 33.1119 & -92.1474 & 56.5 & 110.13 \\
AOT & Old Town Lake & 34.4137 & -90.7879 & 226.69 & 265.47 \\
AFR & Lake Frierson & 35.973 & -90.7192 & 361.42 & 383.54 \\
AMW & Magnolia WWTP & 33.2672 & -93.2699 & 49.89 & 4.2 \\
\hline
\end{tabular}



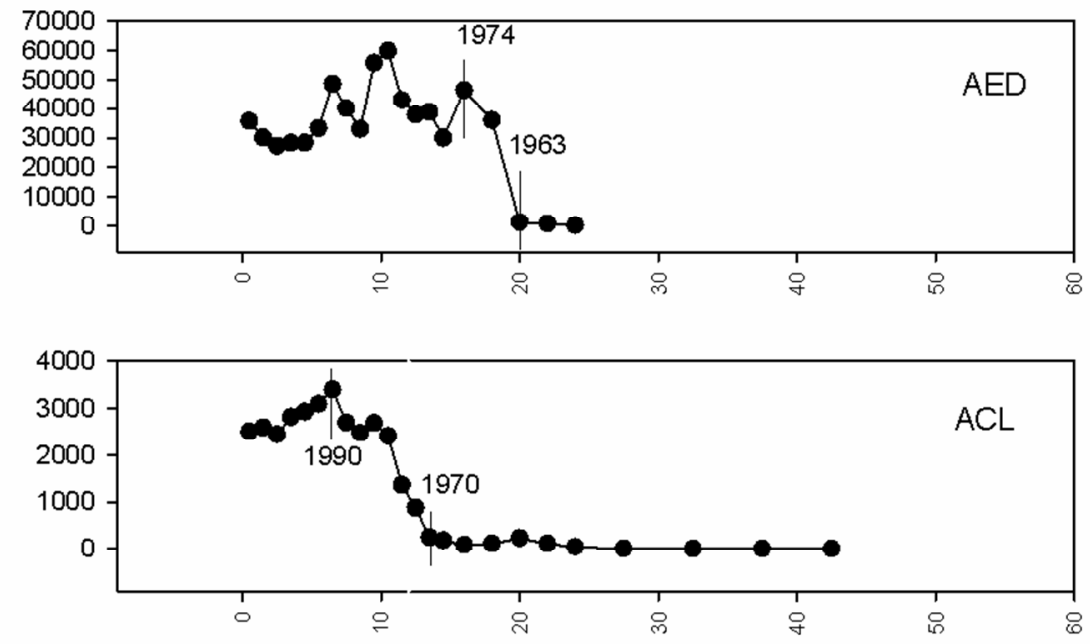

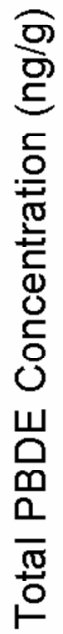
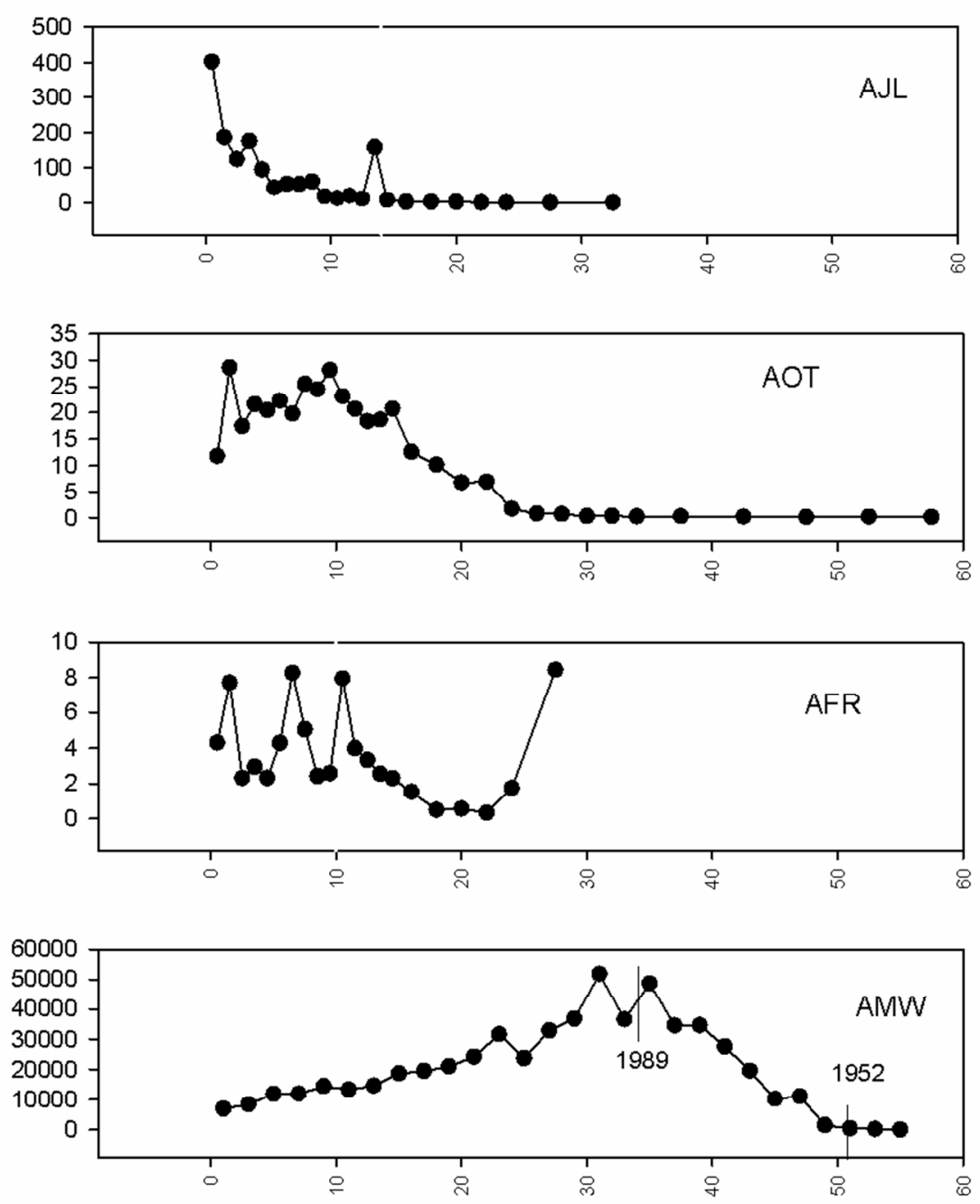

Sediment Layer $(\mathrm{cm})$

Figure S2. Total PBDE concentrations in Arkansas sediment cores. 


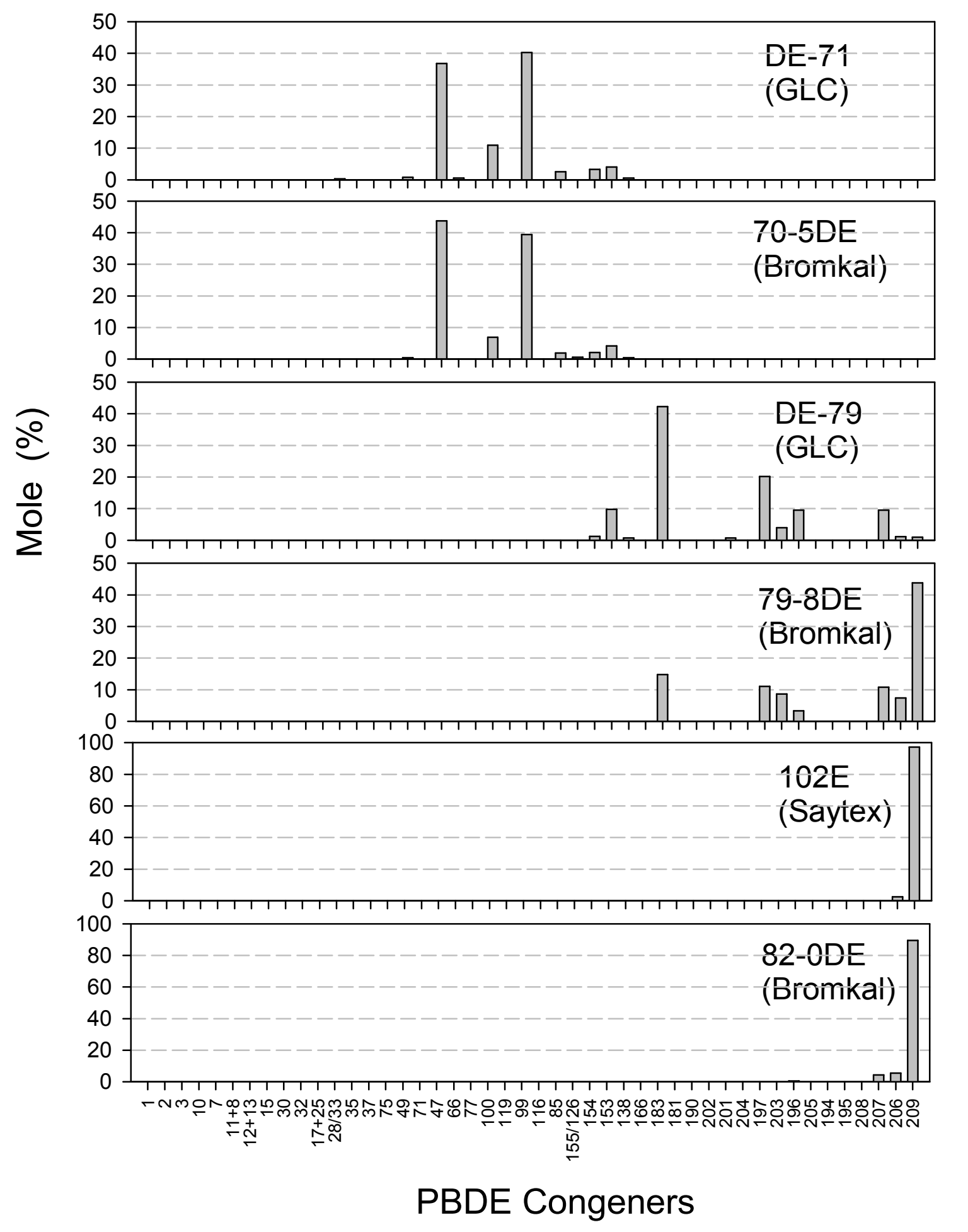

Figure S3. Six common PBDE technical mixture Profiles (La Guardia et al., 2006). GLC represents Great Lakes Chemical Corporation, which is now a subsidiary company of Chemtura Corporation. Bromkal is the trademark of PBDEs owned by Chemische Fabrik Kalk GmbH Corporation. Saytex is the trademark of deca BDE owned by Albemarle Corporation. 


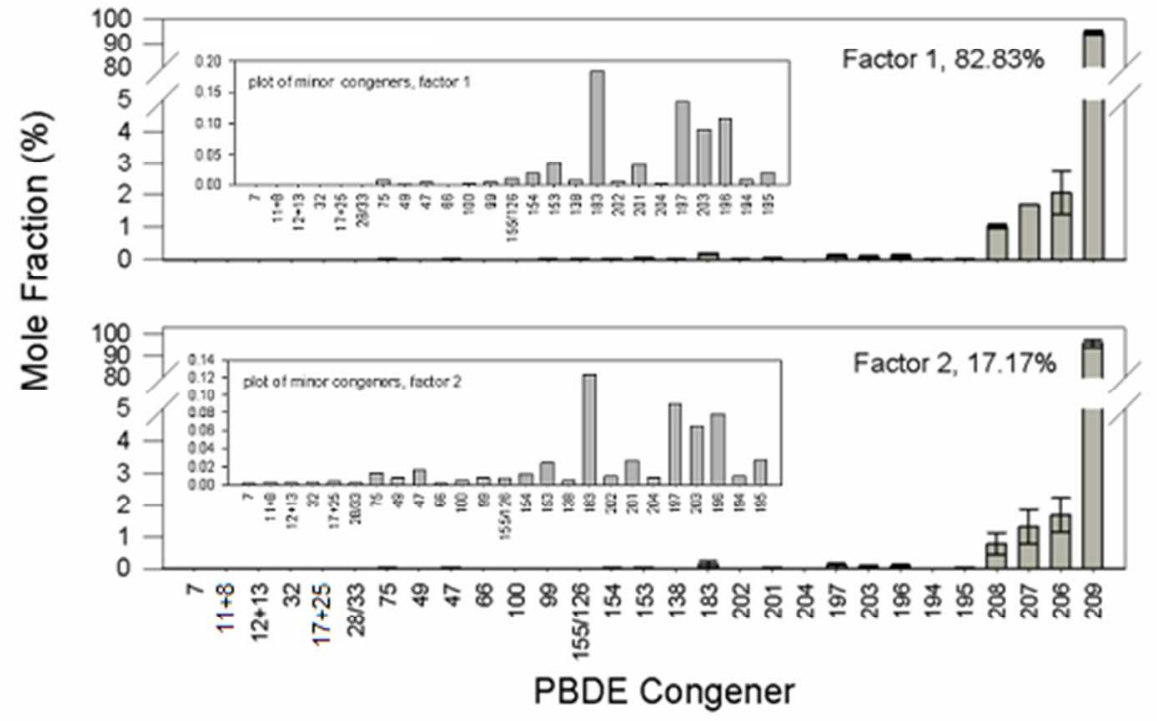

Fig. S4. AED+ACL 2-factor positive matrix factorization (EPA-PMF) fingerprints. 
(a) Factor 2/Total PBDE, AED

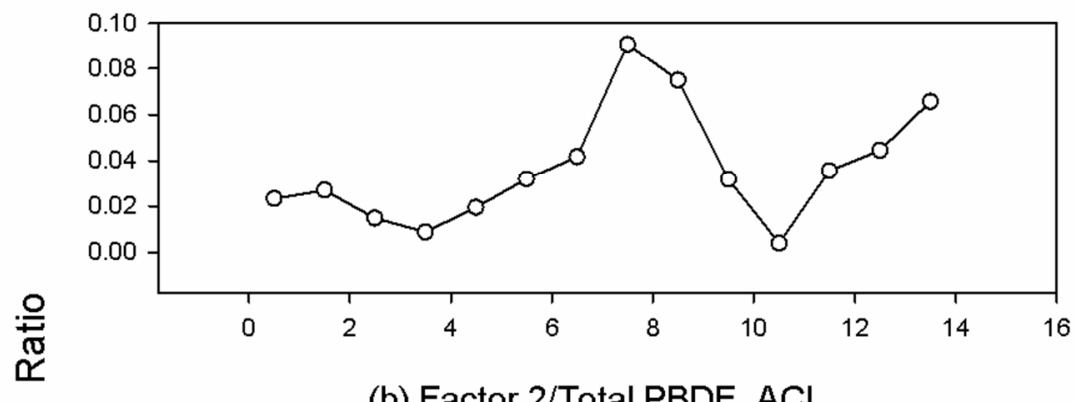

(b) Factor 2/Total PBDE, ACL

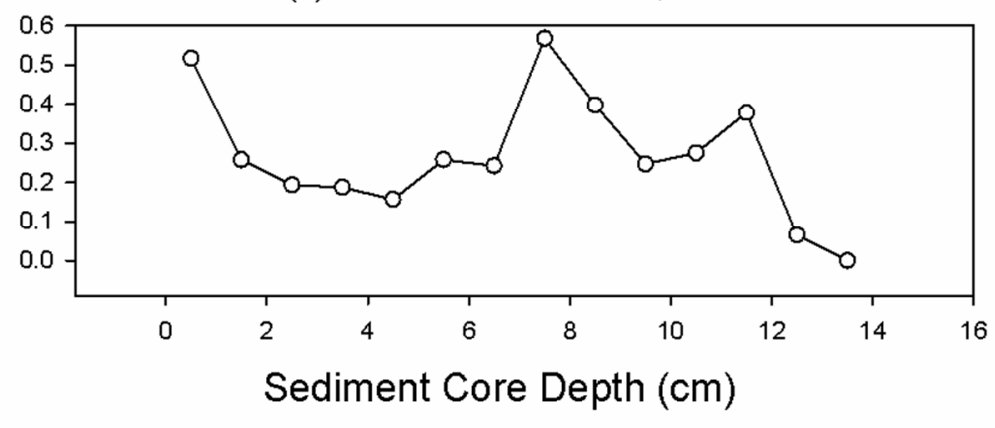

Fig. S5. Ratio of B-PMF factor 2, BDE-209 debromination factor (ng/g), over total PBDE concentration (ng/g), (a) for AED, and (b) for ACL. 


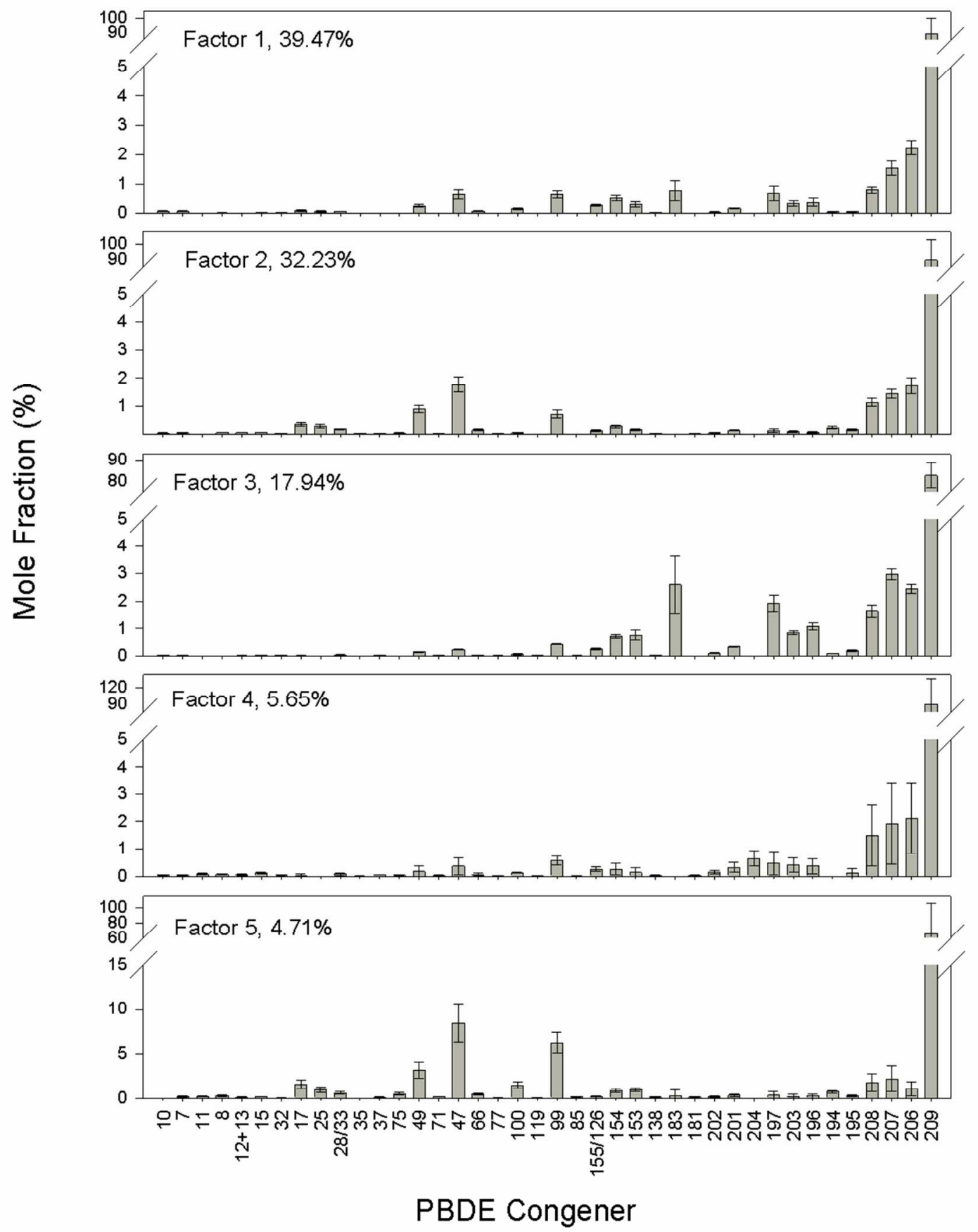

Fig. S6. AMW 5-factor fingerprints (EPA-PMF) 


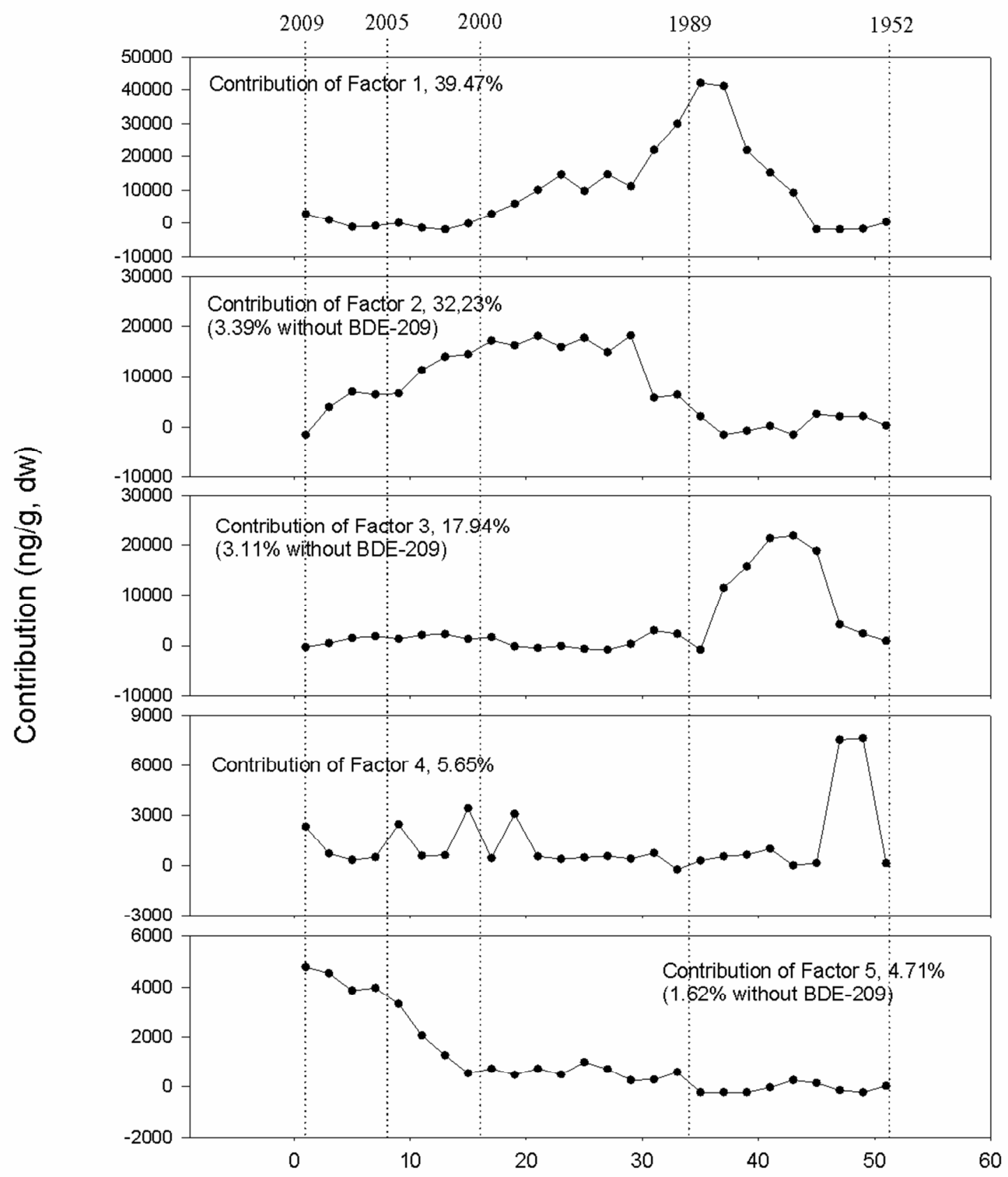

Sediment Core Depth (cm)

Fig. S7. AMW 5-factor contributions (EPA-PMF) 

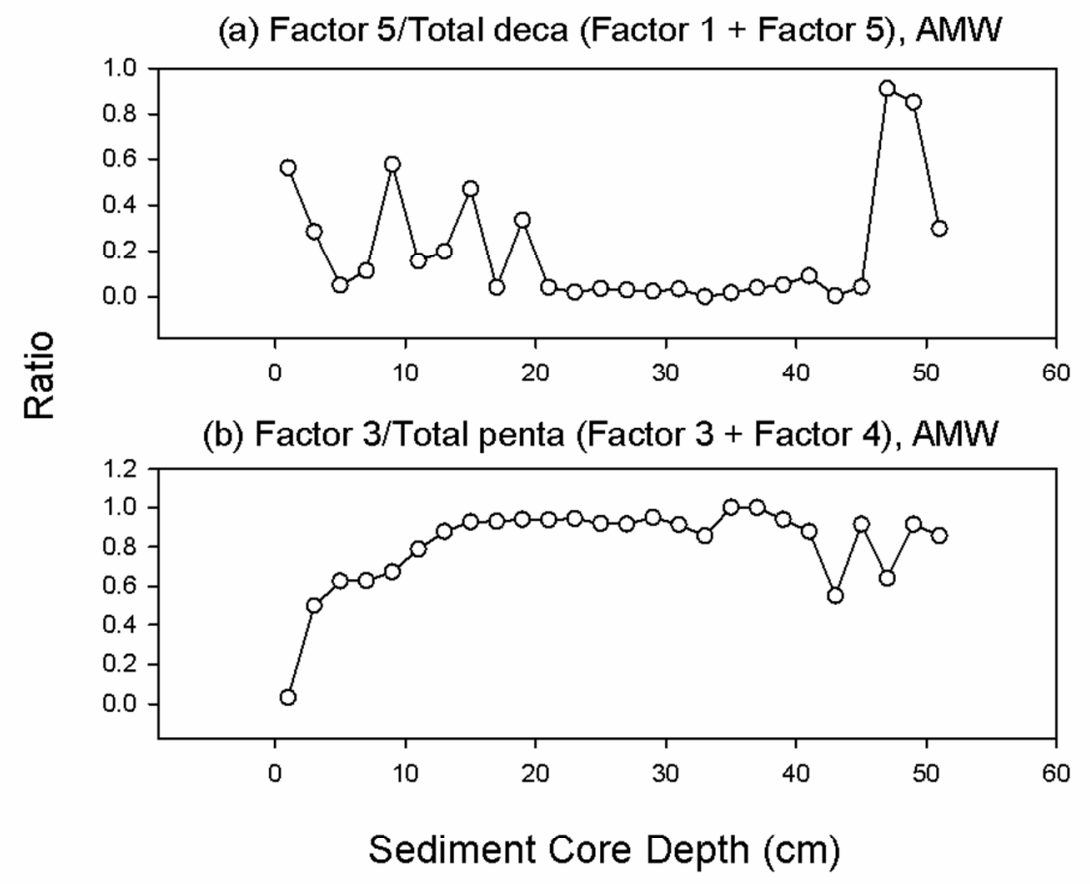

Fig. S8. Ratio of debromination B-PMF factors 5 and 3 to sum of debromination and related non-debromination factors (a) $1+5$ and (b) 3+4 for core AMW. 